\title{
Insurance against Natural Hazards: Critical Elements on the Risk Premium Evaluation in the Italian Context
}

\author{
Andrea Jonathan PAGANO ${ }^{1 *}$, Francesco ROMAGNOLI ${ }^{2}$, Emanuele VANNUCCI $^{3}$ \\ 1,2Institute of Energy Systems and Environment, Riga Technical University, Azenes iela 12/1, \\ Riga, LV-1048, Latvia \\ ${ }^{3}$ Department of Business and Management, Pisa University, Cosimo Ridolfi street 10, Pisa, 56124, Italy
}

\begin{abstract}
The aim of this paper is to highlight the insurance dynamics in relation to catastrophic events and how the insurance companies approach the insured parties (contractors) for the definition of a tailored insurance policy contract. Within this study the emphasis has been addressed more on the regulatory situation in the Italian context as a key example of the existing contractual problems regarding the drafting of insurance contracts against natural hazards. In particular, the study defines the drawbacks of having information asymmetry between the parties towards several substantial elements of the policy agreement, including the definition of the overall risk, exposure, vulnerability and the consequential insurance premium. This study provides an overview of the possible calculation as a specific one based on the risk / premium assessment tool of the Exceedance Probability curve (EP curve) method used by insurance companies. This method focuses on some of the most important insurance parameters for determining the insurance premium and the possible indemnity in relation to the risk related to natural hazards. In the results and discussion, the research reports on how an information discrepancy on contractual transparency appears evident in fact creating an obstacle to facilitate the access to the data referred to in the risk calculation inherent in the asset and obviating the information discrepancy, allowing the private individual to use the information consciously. With the presentation of a risk calculation tool based on the EP curve and relative loss or exceedance, the study shows a possible correlation between insurance dynamics and the new environmental, social, governance (ESG) parameters for implementation on the financial markets.
\end{abstract}

Keywords - Insurance company; natural hazard; risk and resilience

\section{INTRODUCTION}

In recent years, the insurance industry has undergone considerable losses due to extreme weather events. The year 2011 is considered a record year for natural disasters, with insured claims that have cost the industry more than 127 billion dollars. Moreover, according to one of the latest reports on Europe drafted in 2013, it has shown that EU has experienced a global amount of $€ \$ 33$ billion of losses, for which about $50 \%$ have been paid by insurance companies [1].

A series of catastrophes in the late eighties and early nineties of the last century has placed a great challenge on the insurance industry.

* Corresponding author.

E-mail address: andrepaga23@live.it 
With an emphasis on the Italian context, the Italian Statistical Bureau Centre (ISTAT) revealed that in $2015,19.61 \%$ of the Italian population was exposed to flood risk (with peaks of $53.16 \%$ in the North-East), $4.10 \%$ to landslides, while in 2016 about $8.92 \%$ of the territorial area of the Italian peninsula has been classified as a high seismic area. In front of such evidence it would be essential to better evaluate how the community could strengthening its capability to withstand against hazards triggering potential natural disaster [2]. In this light insurance represents an effective mechanism to move towards more tailored and customized risk reduction strategies.

If the dynamics, in terms of prevention within a territory, are addressed more towards government and administrative management, the role of insurance, in terms of limiting damage and mitigating the consequences of "weak contractors", is certainly paramount.

This study highlights the unfavourable position, [3] from a contract-definition perspective speaking, of the insured subject against the insurance company in order to denounce the disparity in the knowledge of the two parties involved in the contractual dynamics and to propose a constructive approach towards the total sharing of the data that insurance companies benefit from in preparing the very first draft of the contract de quo.

The approach, as outlined above, concerns the awareness, among others, of the weak party issue when entering into contracts and the lack of transparency in drafting the insurance contract. The proposition is inherent in the possible implementation of a general information model.

In particular, the insured person does not know the process that leads the insurance company to draft and draw up the contract. [4] With regard to the third methodological point of the methodology of the paper, i.e. the EP curve, the insured subject is not aware of the inherent and innate variables, such as the probabilities connected to the occurrence of an event, the maximum tolerable loss threshold of the insurance company or even the algorithmic dynamics referred to in the definition of the consideration to be charged to the insured party.

The study was motivated by the increasingly pressing need, as well as by the obligation, to date not yet respected, to provide the "weak" contractor with a complete picture of the legal and financial aspects that involve the contract itself. The aim concerns of contributing to highlight the responsibilities and duties attributable to the insurance company, as well as, consequently, the rights, continuously injured and limited, of the insured subject. In particular, the whole paper is in the light of according to a civil perspective to sensitize the mass media and the subjects involved to build the basis of a new systematic approach to defining and drafting insurance contracts against natural hazards.

The pressing need described in the above paragraph is highlighted as evidenced by the compulsive and continued production by European public bodies of directives and provisions in the insurance field on transparency and contracts, such as the Directive (EU) 2016/97 (https://eur-lex.europa.eu/legal-content/EN/TXT/PDF/?uri=CELEX:32016L0097\& from=EN) the so-called Insurance Distribution Directive or "IDD" that regulates the way insurance products are designed and sold both by insurance intermediaries and directly by insurance undertakings.

\section{RESEARCH METHODOLOGY}

The research approach within this paper is based on both a consistent analysis focused on relevant outcome from research and on grey literature.

Specifically for this paper, the methodology is addressed in four areas of study. The first one, concerns the analysis of data referred to natural disasters focused on the Italian context. 
This analysis consists of research on specialized websites in data processing, in particular, with regard to the Italian theme, the authors are focused on the latest ISTAT (Italian Statistical Bureau) data [5].

The second part relates to the dissemination of insurance dynamics in Italy in general and, in particular in regard to natural hazards. The focus is oriented on the normative study and the explanation of the general methods of calculation of risk and premium and focused on the systematic study of insurance dynamics from the point of view of the company in the elaboration of the contract.

The third methodological step was addressed in the study of insurance dynamics in the elaboration of the drafting of the EP curve. The connection between the first two methodological areas and the drafting of the curve EP concerns the case in which the aforementioned curve allows the insurance company to calculate the risk, or rather, as explained more extensively below, the percentage of times in which a loss exceedance occurs. This aspect, in addition to highlighting the usefulness of this tool, also shows the information discrepancy and, above all, the advantages that the weak party could have in cases where the data referred to in the curve were available and clear.

The fourth area of study concerns the possibility, merely experimental and hypothetical, of the possible application of Environmental, Social, and Governance ESG parameters in the reduction of catastrophe risk. The last methodological aspect concerns the study of some of the most important parameters introduced in recent years in the insurance and financial sector, in particular the analysis focuses on ESG criteria, which are mainly used to screen potential investments. Environmental criteria consider how a company performs as a natural factor. Social criteria examine how it manages relationships with employees, suppliers, customers, and the communities where it operates. Governance deals with a company's leadership, executive pay, audits, internal controls, and shareholder rights. The analysis that has been carried out consists in establishing a parallel between the standard operations underlying the ESG criteria and the insurance dynamics, showing points of contact and new opportunities for private and public investors.

\section{General Framework on CONTRACTUAl InSURANCE Regulations in THE ITALIAN CONTEXT}

In insurance matters, except for the Italian Insurance Supervisory Institute (IVASS) decisions and EU Directives, the information obligation on the truthfulness of the data inherent to the risk and insuring asset is generally recognized exclusively as a burden of the insured party. The insurance contract originates from the truthful information that the insured party is charged to communicate to the insurance company [6].

The insured party, during the transaction referred to as the negotiation for contractual completion, must comply with some duties, including the general one in order of the context of conducting the negotiation in good faith. With reference to that, during the pre-contractual phase pursuant to article 1337 of the civil code of Italy and by additional charges specifically determined for the stipulation of the insurance contract, both parties must respect the civil law determinations

In particular, the insured party must report clearly and without reticence to the insurance company all circumstances that may affect the probability of occurrence of a risk and its possible consequences, drafting, indeed, a description of the risk tout court. Articles 1892 and 1893 of the civil code of Italy (c.c.) describe in a clear and precise way the statements 
that must be complied to by the insured, delimiting the consequences for a possible breach of contract (non-fulfilment) [6]. These regulations provide that the insured is obliged to report to the insurer any relevant situation on the risk: if the subject is not intentionally culpably or intentionally grossly negligent the contract is voidable, while in presence of slight negligence the contract is valid and effective, but the insurer is granted a unilateral right of withdrawal. The insurer has a short period of forfeiture, to withdraw from the contract, if it occurs the awareness of the false declarations of the insured, before the loss should occur, or by the exemption from the obligation to pay, if the claim occurs before the false declaration is discovered.

These provisions on the subject of pre-contractual information have a ratio both of a "public" and "private" nature. The main question of the problem from the "res publica (public)" point of view is to give insurance companies the opportunity for an appropriate and early assessment of the risks they take.

Shortly, the insurance market that works correctly is the one in which any risks are divided and allocated among several parties. [7]

According to the Italian Supreme Court (Corte di Cassazione 13.3.2007, n. 5849), the knowledge of the risk is fundamental for the insurer in order to evaluate the insurable assets from the point of view of the insurance assessment, in order to provide the exact determination of the premium within the framework of the so-called "neutralization of risks" and allocate it in a category of homogeneous risks.

From the "private" side in the insurance contract there is the concrete possibility of an information asymmetry, in fact from some points of view the insured is the weak party of the negotiation, while for others the insurer can be considered the weak subject of the negotiation. From the contractor's point of view, being a subject that does not exercise the insurance business professionally might be considered as a disadvantage in terms of negotiations. Furthermore, it must be added that the contract is completely prepared by the insurer and therefore the margins for setting up a negotiation often do not take place for the contractor.

The insurance code can aid the contractor in terms of art. 166, paragraph 1, which declares that the contract must be drawn up in a clear and comprehensive manner, and further, in the second paragraph of the same article, it states that the clauses that indicate forfeitures, nullity or limitation of the guarantees and charges to be borne by the insured person, must be reported using characters and terms with particular evidence [8].

From the point of view of the insurer, despite the fact that the company itself prepares the contract, it is required to provide all the information regarding the risk. However, theoretically, such intel is in the hands of the contractor who may not make incorrect declarations in order to pay a lower premium.

In the insurance contract, the pre-contractual declarations represent a more important part than the other contracts, even if this contract is always subject to the general discipline of art. 1337 c.c.

In light of this, the insurance contract is defined as an uberrimae bonae fidei contract, i.e. a contract that requires the maximum sincerity, transparency and trust between the parties. There are several theories about the nature of the duty of the insured to describe and declare the entity of the risks inherent to the asset.

The prevailing thesis, confirmed also by the Supreme Court of Italy, declared that the description of the risk constitutes for assuring a real obligation arising from the law, as this obligation is of a precontractual nature as the declarations regarding the risk must be made during the negotiation for the stipulation of the insurance contract. As mentioned above, this 
orientation, was confirmed by the Supreme Court, which in several decisions argued that this is a pre-contractual obligation.

The uncertainty and the randomness about the actual occurrence of the event must be verified and measured, both by the insurer and by the insured so that it would be convenient.

From the insured person's point of view, it is fundamental to understand whether to pay the gross premium immediately and to acquire the right to any compensation for damages.

From the insurer's point view, it is equally fundamental to evaluate whether to immediately receive a fee, the net premium, and to pay, in the future, compensation for the damage connected with the occurrence of the event.

The first focal point that the author wanted to highlight in this paragraph is precisely represented by the clear information asymmetry that takes place whenever an insured person, in the first place, does not have full knowledge of the totality of the hidden and manifest risks with regard to the asset, secondly, when the insurance company presents a contractual, unilaterally drafted facsimile, in which the calculation of the risk and the premium are not known by-the weak party [9].

\section{General Framework on Contractual Insurance Regulations AGAINST NATURAL HAZARDS IN THE ITALIAN CONTEXT}

The second part of the paper focuses on the application of the legislation and the information asymmetry when the asset and the insurance relate to natural hazard or, more generally, to risks related to natural hazard that can trigger catastrophic effects.

The risk related to the asset belongs to the insured person, who must fulfil the obligation of information by means of the aforementioned declarations, net of actual and presumed knowledge of an extremely complex risk like that of natural hazards.

For the purposes of the regulations referred to in art. 1892 of the Italian Civil Code, in order to define the risk, it is exclusively the insured party's reticence that has value and is sanctioned. In fact, if a harmful event occurs, even if these circumstances did not directly affect the occurrence of the risk, the application of the regulation in question shall stand and be binding, as there is a connection between the inaccurate declaration and the consensus of the company [10].

As regards the assessment and evaluation of the relevance of the inexact declaration or of the reticence, this assessment must be objective, therefore generally acceptable criteria must be used for the evaluation. Therefore, to carry out the assessment, only those inaccuracies that affect the representation of the risk must be taken into consideration. Therefore, the legislation does not take into consideration the actual causal link between the incorrect declaration and the harmful event, but rather the mere incorrect representation of the risk connected and correlated to the asset [11].

As for catastrophic events, from the point of view of the company the element of impossibility exists of gathering reliable information from the weak party and a similar possibility that the asset to be insured can be exposed in various degrees to one or more natural hazards, whereby insurance companies have difficulty to ascertain the demand for coverage and to have success in providing this coverage, due to the excessive cost of the premiums [12].

One of the first legislative measures put in place by the Italian legislator was introduced at the beginning of the 2000 s and focused on the aspect of insurance coverage in the agricultural sector. The Legislative Decree 102/2004 wanted to incentivize the stipulation of insurance 
coverage in the agricultural sector, through the provision of state contributions. In addition to the use of state contributions, the Ministry of Agricultural, Food and Forestry Policies in Italy has approved the agricultural insurance plan.

The plan, renewed and proposed every year, aims to extend and make insurance coverage more accessible, to protect against atmospheric damage and weather.

Every year this plan establishes minimum standards for the stipulation of policies to cover the risks for breeding and agriculture. It also makes state grants available to make insurance premiums accessible.

A few years after this measure strictly directed towards agricultural policies was introduced, the legislator has ruled on the introduction of a policy measure in order to develop a more general regulation of insurance on immovable assets exposed to natural hazards. The legislative decree 59/2012 (converted with Law 12 July 2012, n. 100) allows the use of insurance policies against any type of damage to buildings against the risks deriving from natural disasters. The above regulation is understood to establish measures to encourage the stipulation of insurance policies, including the exclusion, even partial, of state intervention for damage to buildings and tax incentives [13].

The use of insurance policies against catastrophe risks can be useful to reduce public spending in the event of catastrophic environmental events, as well as a tool to limit lack of transparency in claims for compensation [14].

Moreover, in the policy conditions, according to the law, it is advisable to insert the conditions of insurability that can reduce the harmful events and encourage the quantification of the premium and of the same operation of compensation for damages.

In light of the general provisions, a specific case can identify a gap that is the case by which a subject may not legitimately be aware of the necessary and prodromal data to provide the mandatory information referred to in the declaration that the insuring must lend in favour of the insurance company [15].

Starting from the assumption that it has been possible to experiment and devise insurance instruments against natural hazards, it is possible to highlight some characteristics.

Preliminarily, it appears necessary to highlight that, apart from the obligation to ensure certain risks (as for the Civil Car Liability in Italy), the insurance contract assumes that there is convenience to its stipulation from both the point of view of the parties. At the base there must be uncertainty about the occurrence of well-defined events.

The problem of insurance of catastrophic risks is primarily a problem of being insurable in a technical sense, although it is also relevant from a legal point of view [16].

Technical insurance depends on an assessment of the insured risk carried out according to specific insurance parameters other than the judgment of insurability in a legal sense understood as the compliance of the insurance coverage with the legal system.

It must be said that this distance of concepts finds second thoughts on the part of the proponents of the theory that sees in the insurance company a structural element of the insurance contract, or a necessary tool for the realization of the contractual economic operation. In this way it is possible to conclude that the insurability in a technical sense, as a necessary condition for risk management by the insurance company, is also a prerequisite for the implementation of the proper function of the recognized insurance contract worthy of protection of the case. The relationship between technical insurability and legal insurability also arises with regard to coverage of catastrophic events, where the technical and economic risks of risk management find consideration, to some extent, by the legislative regulations [17]. 
With specific reference to the coverage of catastrophe risks, the Italian legislator opted for a reference to the autonomy of the predisposing party. In Article 1912 c.c. in fact, it is expected that "earthquake, war, insurrection, social turmoil" are excluded from coverage in non-life policies "unless otherwise agreed". The rule is placed within the title on "damage insurance".

Nothing is outlined in the area of life policies, if the Italian Insurance Supervisory Institute (ISVAP now IVASS) recently mentioned that, in setting the minimum contents of life insurance contracts linked to mortgages, it also provided for the exclusion of death due to catastrophic risks (see ISVAP Reg. 40/2012) [18]. The exclusion of these risks must therefore be considered as present in the contract, unless otherwise agreed, according to a legal integration mechanism. It follows that the subject covered by a policy for damages, where coverage of catastrophic events is not envisaged, will not claim any indemnity towards the insurer in the event of a claim caused by events of this nature. Something different can however be said where the insurer is found to be in breach of specific information obligations in favour of the contractor, the insured and the beneficiary. According to art. 31 of the ISVAP regulation 35/2010, as set in implementation of the art. 182 cod. ass. (Private Insurance Code - Legislative Decree No. 209/2005), it is envisaged that "in preparing the pre-contractual and contractual documentation the companies illustrate, with particularly evident graphic character, the clauses that provide for charges, obligations and exclusions" [19].

If it is considered that the law should also be extended to legal exclusions, according to the orientation recently followed also by the legislator, then also the exclusion pursuant to art. 1912 must be literally included and highlighted in the contractual and pre-contractual documents. It remains to be established which is the consequence of the violation of said rule of conduct.

According to the majority jurisprudential orientation, consequences will be on the compensation plan compensating the contractor (the insured or the beneficiary) for the failure to fulfil his / her own interests. In this case, the customer will be entitled to a sum of money corresponding to what he/she would have received if the exclusion had not been effective. It must be said that in general the insurance policies contain limitations of coverage. The problem is sometimes that of an "excess" of exclusion. Thus, in the presence of a contractual clause which provided for the exclusion of damage to buildings "due to settlements, collapses, landslides or vibrations of the ground from any determined cause", the Supreme Court of Italy ruled in the sense of the voidness of a similar limitation based on art. 1229 of the civil code, setting up the same, given the extent of its scope, an exemption from liability and not a causal delimitation of the risk [20].

Based on this analysis, it could be pointed out that, in accordance with the insurance dynamics against natural hazards, information asymmetry becomes more acute when the asset and the risk connected to it are not easily known and calculable by the weak party.

Within this scenario, which is heterogeneous and devoid of orderly and precise regulation, therefore, we highlight the case of a context in which the parties, in particular the insured, do not actually have the right to fully define the risk factors and damage inherent in an asset exposed to natural disaster [21]. 


\section{Framework ON InSURANCE DyNAMics Against NATURAL HAZARds. CAT-MODELS}

The insurance industry over the years has implemented so-called catastrophe models (CATMODELS) to mitigate and, within limits, control catastrophe-derived damages. The adoption of models for natural catastrophe scenarios, since the 1990s, has allowed the industry to analyse and measure risk more accurately.

Today, the use of these models became the norm. In particular, one of the most important models in regard to mitigation of risk against natural hazards corresponds to the drafting of the EP curve. In fact, the EF curve allows the insurance company to verify and outline: 1) the probability that a given hazard affects one or more portfolios of buildings or immovable assets; 2 ) the maximum loss borne by the insured person with regard to the data processed by the system [22].

Given the prevalence of templates for catastrophic scenarios in insurance and increasing costs of extreme weather events, the accuracy of the results of modelling is a primary concern for insurers.

It is worth noting and adding that the cost to be charged to the insurance in the event of a catastrophic natural event implies a considerable disbursement by the company itself, and also for this reason, as well as avoiding the physiological insolvency, the phenomenon of socalled reinsurance in recent years has grown considerably [23].

The possibility that climate change might facilitate changes in the gravity and probability of extreme weather events could affect the accuracy of the models for natural catastrophe scenarios [17]. This scientific paper assesses whether and how these models consider climate change through a series of case studies contributed by various providers to both academic and commercial models [24]. Catastrophe modelling approach contains a specific view of the operators for the hazards, risks and the vulnerability of the insured goods. This view has been designed using the observed data as a base [25]. The above approach facilitates the application of this risk to view records of a particular customer, in order to quantify the probability and magnitude of the potential loss. This is achieved by reducing the complexity inherent in the physical interaction between hazards and vulnerability, by parameterizing the features in a limited set of measurable units [26]. These units are applied systematically, consistently and repeatedly in a custom set of exposure data. Financial characteristics related to the insurance sector can then be superimposed to calculate a net loss tailored to the client using the tool. Use of the above approach is however only a small fraction of what is needed to optimize the use of catastrophe modelling within an activity [27].

As highlighted in the previous paragraphs, one of the sections of the paper is dedicated to one of the most popular tools in insurance companies for calculating risk and maximum loss, including the type of risk associated with natural hazards.

In the next sections an insight about quantitative aspects on the assessment of risk insurance is proposed through the description of the definition of the Exceedance Probability curve and its main bottlenecks. 


\section{Elaboration OF THE EP CURVE AS A TOOL FOR InSURANCE COMPANiES FOR Risk REDUCTION WITHIN A CONTRACTUAL CASE AgAINST A NATURAL HAZARD}

Catastrophe scenarios, here specifically in terms of natural hazards, can provide different financial results, the most common of which are the curve of average annual loss (Annual Average Loss, $A A L$ ) and curve of probability of exceedance (Exceedance Probability, EP) [28]. The $A A L$ is sometimes called "pure" or "claims report award/awards" and can be incorporated into the pricing together with an allowance for expenses and the return on capital [29]. The curve $E P$ is commonly described as a graphical representation of the probability that a loss produced by possible events, namely here natural hazards, exceeds a certain amount [30]. Reading points on the curve offer different interpretations in the frequency and severity of losses.

These curves are very useful to insurers and reinsurers to determine the size and distribution of potential losses of their portfolios. The EP curve allows insurers to determine the probable maximum loss (hereafter referred to as $P M L=$ Probable Maximum Loss) for a portfolio of buildings in a certain timeframe due to a natural hazard occurrence. The insurer determines first the percentage risk it deems acceptable then checks the total loss amount for that specific probability level on the curve EP [31].

It appears absolutely essential for continuation of the discussion that the authors conduct and deal with the theoretical questions described above in a table and a graph so that the way in which the insurance companies determine the risk and the price starting from a numerical base is, partially, clarified, i.e. the determination of the percentage of exceedance probability [32].

The practical example is the assumption that there is a set of catastrophic events $\left(E_{i}\right)$ that can jeopardize an immovable asset's portfolio. Each event has an annual probability when it occurs $\left(p_{i}\right)$, and a loss associated with it $\left(L_{i}\right)$. Furthermore, it must be considered that there is the possibility that more than one event might occur the same year. The table below takes as assumption eight events which are ordered in accordance with decreasing total losses $(L)$. The sum of the probabilities of all events must be equal to 1 .

TABLE 1. HYPOTHETICAL EP CURVE DEFINITION

\begin{tabular}{lllll}
\hline $\boldsymbol{E}_{\boldsymbol{i}}$, step & $\boldsymbol{P}_{\boldsymbol{i}}, \boldsymbol{\%}$ & $\boldsymbol{L}_{\boldsymbol{i}}, \boldsymbol{\epsilon}$ & $\boldsymbol{E P}\left(\boldsymbol{L}_{\boldsymbol{i}}\right), \boldsymbol{\%}$ & $\boldsymbol{E}[\boldsymbol{L}]=\boldsymbol{p}_{\boldsymbol{i}} \boldsymbol{L}_{\boldsymbol{i}}, \boldsymbol{\epsilon}$ \\
\hline 1 & 0.005 & 1000000 & 0.00500 & 5000 \\
2 & 0.015 & 750000 & 0.01993 & 11250 \\
3 & 0.02 & 500000 & 0.03953 & 10000 \\
4 & 0,05 & 300000 & 0.08755 & 15000 \\
5 & 0.1 & 200000 & 0.17880 & 20000 \\
6 & 0.2 & 100000 & 0.34304 & 20000 \\
7 & 0.25 & 50000 & 0.50728 & 12500 \\
8 & 0.36 & 10000 & 0.68466 & 3600 \\
\hline Total: & $\mathbf{1 . 0 0}$ & & & $\mathbf{9 7 3 5 0}$ \\
\hline
\end{tabular}


The expected or predicted loss in relation to a given event $\left(E_{i}\right)$ over a timeframe equal to a year is:

$$
E(L)=p_{i} \cdot L_{i}
$$

The total expected losses for the entire set of events, namely the average annual loss (hereinafter $A A L$, as also reported in Table 1), is substantiated by the weighted sum of expected losses for each event and the probability that event will occur. $A A L$ is defined as below:

$$
A A L=\sum_{i=0}^{n} p_{i} \cdot L_{i}
$$

If only one event takes place during the year, it is possible to determine the EP curve, i.e. the expressed loss value, as follows:

$$
\begin{gathered}
E P\left(L_{i}\right)=P\left(L>L_{i}\right)=1-P\left(L<L_{i}\right) \\
E P\left(L_{i}\right)=1-\prod_{i=1}^{n}\left(1-p_{i}\right)
\end{gathered}
$$

From Eq. (6) it can be deduced that the EP as shown in Fig. 1 curve is the annual probability that a loss exceeds a certain value, which is equal to 1 the probability that all other natural hazards below this value will not occur.

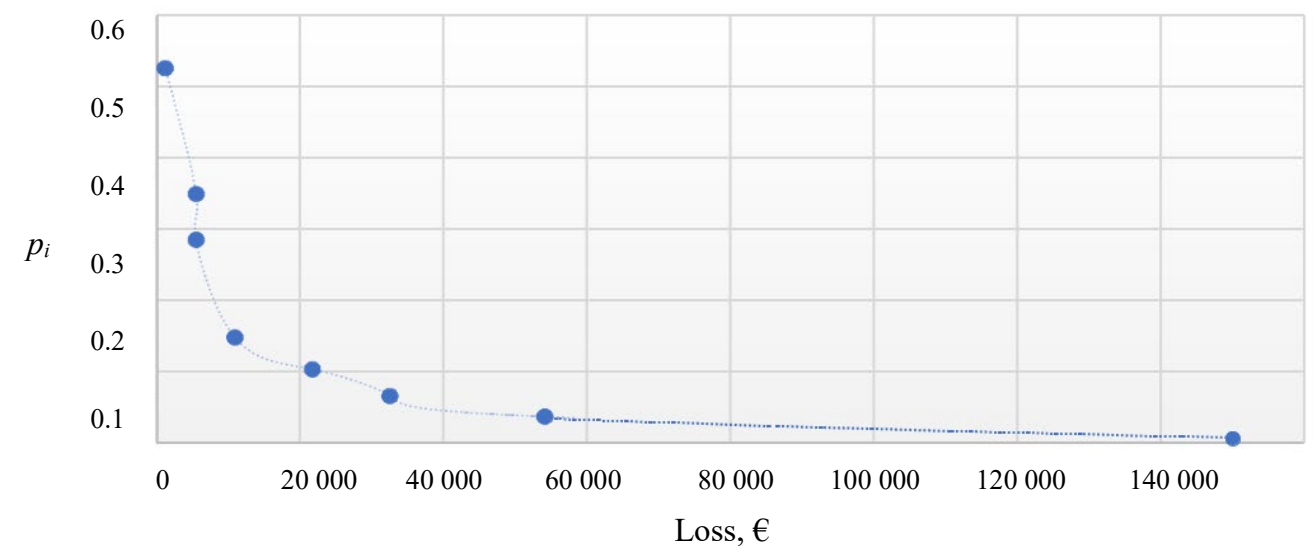

Fig. 1. Theoretical EP curve draft according to Table 1 data.

The elaboration proposed by the authors on the calculation of the $E P$ curve concerns the calculation of the risk as well as the maximum loss drafted by the insurance company. In particular, the authors, as highlighted by illustrious colleagues, even in heterogeneous fields believe that to date there is a need for risk awareness, greater data sharing and implementation of the transparency referred to in the contracts [33].

It is necessary, in order to allow the weak party to have greater knowledge and awareness of the risks associated with natural hazards, that the insurance companies share the calculation method in a simple and clear manner also, among others, in full compliance with European and national regulations [34]. 
Ultimately, it is essential for the weak party to understand the incidence of EP curves in relation to the elaboration of the premium, in relation to the asset, the exposure and the perception of the risk against natural hazards [35].

The relationship between the empirical section referred to in the curve EP and the lack of information highlighted above underlies the possibility for the weak contractor, in conclusion, to obtain an equal, at least theoretically, contractual position with the insurance company

\section{THE ESG EXPERIENCE. A NEW EUROPEAN APPROACH}

The lack of experience and data relating to risk - to be used in the determination of premiums - is well known especially where a real insurance market is still lacking and underdeveloped [36] (for example, cyber risk or so-called NATCAT for some natural events) or when it is not possible to refer to comparable products. In the absence of reliable data for the evaluation of the premium, the subject appointed by the insurance company must be cautious in developing the rates in order not to compromise the overall balance of the portfolio and, subsequently, to verify over time the correctness of the choices made.

Data processing programs often do not include sustainability variables such as Environmental, social, governance (ESG): using these parameters can be very interesting for optimizing risk management and avoiding an excessively prudent and conservative attitude and making informed investment choices [37].

To undertake to reach a solution, a different cultural approach seems necessary, capable of deeply motivating the subjects involved in the insurance dynamics, developing in-depth knowledge, trying to understand the nature of these data and their close correlation with the possibility that the harmful event envisaged in the contract occurs [38]. The meaning of the cultural approach is inherent in the necessary regulatory-systematic change of direction described above as well as, of course, in better information on the rights of both parties in the drafting of the contract.

Looking towards a supranational context, the European Commission, for example, has promoted and developed the H2020 NAIAD project [39] to collect and analyse data and information for the creation of a platform in which new insurance instruments or investments are made - to counteract the risks deriving from floods and droughts - in which the prevention, management and resilience measures adopted (the so-called Nature based solution - NBS) are taken into account.

Similarly, in the same supranational context, even in non-related areas, it has been demonstrated already the correlation between "Sustainability", corporate governance, the value of the assets and the influence it has on a company's share performance [40].

In this respect, the 2014/95 / EU directive (in Italy transposed into law by Legislative Decree No. 254/2016) represents a focal opportunity to consolidate the transparency and publicity of "extra" financial information and hopefully could allow investors, consumers and, more generally, all stakeholders to have, in their respective areas and for their respective purposes, a clear framework for company activities. At the same time, the Financial Stability Board (FSB) has drafted some guidelines to encourage financial operators to provide greater disclosure of information regarding climate change as well as natural hazards, from the point of view of both investors and issuers, as it is clear that such a choice can help companies in the decision-making process and allows stakeholders to understand the impact of climate change on business operations. Reconnecting the last section to what was observed on information asymmetry, and the weak role from the contractual party point of view of the weak party, it is worth highlighting that during the climate change conference conducted in 
Paris in 2015 (https://unfccc.int/process-and-meetings/conferences/past-conferences/parisclimate-change-conference-november-2015/paris-climate-change-conference-november2015) on 8 December 2017, many of the major asset managers, pension fund and insurance companies signed a declaration to support the focal point of the importance of improving the transparency and public disclosure of the ESG rating by issuers, in addition to the Financial Rating [41].

\section{CONCLUSION AND Policy Implications}

The conclusions of the paper can be defined as follows. In the first place, the paper tends to raise awareness of common sense, insurance companies and individuals with regard to information asymmetry in insurance contracts. In particular, by making a general criticism of the informative mode, the initial burden of which is on the weak party, today more than ever, this statement is even more anachronistic and inadequate in the light of a risk that is difficult for an individual to calculate or predict, such as a natural hazard.

Except for very rare exceptions, the insurance contract is seen as a "unilateral" contract in the sense that it is written in its entirety by the insurance company that composes it on the basis and studies of its own derivation, thus leaving the subject assured the mere possibility of outlining the risk, the premium and the object to be insured. Therefore, since the preparatory phase is always the responsibility of the insurance company, with all the consequences that this entails, what are the protections granted to the insured? Even today, a famous Latin phrase dominates the insurance world: Quis custodiet ipsos custodes? Who will guard the guards themselves?

The focal concept is inherent in the age-old problem of awareness that those who delimit the areas of rules and provisions are often not subject to similar checks. Thus, if the insurance company is well aware, or at least theoretically aware of the risks outlined above, outlining the preparatory scheme of the contract in relation to a cost benefit analysis, on the other hand, the weak party has no guarantee that effectively the same checks that were carried out on himself/herself and on the asset are then carried out in reverse on the company itself.

Another point of discussion of the paper concerns one of the methods of calculating the risk used by the companies, namely the EP Curve, highlighting the strengths and weaknesses of such a calculation, also in light of the unilateral nature of the same during the contracting phase. In particular, one of the focal points of discussion and results pertains to the EP curve as a tool for calculating the insurance premium. To date, in the opinion of the authors, this tool should be made understandable and available for the weak party to raise awareness and share the data of the connected risk. In fact, even in compliance with the implementation of supranational regulations, it is no longer acceptable that one or more parties referred to in a given contract have no right and the right to know every single aspect referred to in one or more essential elements of the latter. In particular, using the 2016/97 European directive as a guideline in correlation with the binding provisions of the Italian civil code, it seems appropriate to the authors that the calculation dynamics, including the EP curve, are shown and explained within the information sheet in the precontractual phase.

The final point concerns the Italian perspective of the use of new parameters in drafting contracts and financial/insurance instruments. In particular, the implementation of the aforementioned by means of the introduction of ESG criteria in order to allow greater awareness, product safety and rating reliability, as well as limiting the general information asymmetry exposed throughout the entire paper, seems to be fundamental from different aspects. 


\section{REFERENCES}

[1] Bevere L., Muelle L. Sigma. Natural catastrophes and man-made disasters in 2013: large losses from floods and hail; Haiyan hits the Philippines. Zurich: Swiss Re. 2014:1:52. [Online]. [Accessed 22.10.2020]. Available: https://media.swissre.com/documents/sigma1_2014_en.pdf

[2] NIBS. HAZUS: Hazards U.S.: Earthquake Loss Estimation Methodology. NIBS Doc. N. 5200. Washington, D.C. 1997.

[3] Giovagnoli R., Ravera C. Il contratto di assicurazione: percorsi giurisprudenziali. (The insurance contract: jurisprudential paths). Giuffrè Editore 2011:223. (In Italian).

[4] Crocitto M. Commentario al Codice delle assicurazioni private. (Commentary on the Private Insurance Code). Halley Editrice, 2006.

[5] Istituto Nazionale di Statistica. (National Institute of Statistics). [Online]. [Accessed 22.10.2020]. Available: https://www.istat.it/it/archivio/202943

[6] Bølviken E., Guillen M. Risk aggregation in Solvency II through recursive log-normals. Insurance: Mathematics and Economics 2017:73:20-26. https://doi.org/10.1016/j.insmatheco.2016.12.006

[7] Gambino A. La neutralizzazione dei rischi nella struttura e nella funzione giuridica unitaria del contratto di assicurazione. (The neutralization of risks in the structure and unitary legal function of the insurance contract). 1985. (In Italian).

[8] Amedeo M. Assicurazioni: nuovi precontrattuale obblighi d' informativa Il nuovo Set Informativo ed il DIP Aggiuntivo. (Insurance: new pre-contractual disclosure obligations. The new Information Set and the Additional DIP). 2018. (In Italian).

[9] Sangiovanni V. Dichiarazioni inesatte, reticenze e annullamento del contratto di assicurazione. (Inaccurate statements, reticence and cancellation of the insurance contract). 2014. (In Italian).

[10] Aa. Vv. L'Assicurazione dei Rischi Calamità Naturali. (Natural Disaster Risks Insurance). $7^{\text {th }}$ R.I.B. Conf., November, 2000. (In Italian).

[11] Landini S. Reticenze dell'assicurato e annullabilità del contratto. (Obligations of the policyholder and cancellation of the contract). Resp. civ. e prev, 2011

[12] Campobasso G. F. Diritto commerciale 3. (Commercial law) 3. Utet Editori Dal 1791, 2015. (In Italian)

[13] Grossi P., Kunreuther H. The role of uncertainty on alternative disaster management strategies. International Geology Review 2001:43(5):391-400. https://doi.org/10.1080/00206810109465020

[14] Lin S. K., Chang C. C., Powers M. R. The valuation of contingent capital with catastrophe risks. Insurance: Mathematics and Economics 2009:45(1):65-73. https://doi.org/10.1016/j.insmatheco.2009.03.005

[15] Landini S. Assicurabilità e indennizzabilità dei rischi catastrofali ambientali. (Insurability and indemnification of environmental catastrophe risks). Assicurazioni 2013:19-29. (In Italian).

[16] McAneney J., McAneney D., Musulin R., Walker G., Crompton R. Government Sponsored natural disaster insurance pools: A view from down-under. International Journal of Disaster Risk Reduction 2016:15:1-9. https://doi.org/10.1016/j.ijdrr.2015.11.004

[17] Nowak P., Romaniuk M. Pricing and simulations of catastrophe bonds. Insurance: Mathematics and Economics 2013:52(1):18-28. https://doi.org/10.1016/j.insmatheco.2012.10.006

[18] Porrini D., Schwarze R. Insurance models and European climate change policies: An assessment. European Journal of Law and Economics 2014:38(1):7-28. https://doi.org/10.1007/s10657-012-9376-6

[19] Cherubini M. C. Tutela del "contraente debole" nella formazione del consenso. (Protection of the "weak contractor" in the formation of consent). Torino: Giappichelli, 2005. (In Italian).

[20] Rossi Carleo L. Il diritto all'informazione: dalla conoscibilità al documento informativo. (The right to information: from knowledge to information document). Rivista di Diritto Privato 2004:349-375. (In Italian).

[21] Scoditti E. Regole di validità e principio di correttezza nei contratti del consumatore. (Rules of validity and principle of correctness in consumer contracts). Rivista di diritto civile, 2006.

[22] Kunreuther H. The Role of Insurance in Reducing Losses from Extreme Events: The Need for Public-Private Partnerships. The Geneva Papers on Risk and Insurance - Issues and Practice 2015:40(4):741-762. https://doi.org/10.1057/gpp.2015.14

[23] Motoyama T. Optimal disaster-preventive expenditure in a dynamic and stochastic model. Journal of Macroeconomics 2017:51:28-47. https://doi.org/10.1016/j.jmacro.2016.11.005

[24] Carr T., May A. Focus on alternatives: Catastrophe bonds explained. Schroeders 2011:1-4. https://www.schroders.com/globalassets/schroders/sites/pensions/pdfs/catastrophe-bonds-explained.pdf

[25] World Enviromental Forum. Rischi dei cambiamenti climatici: il ruolo delle assicurazioni. (Risks of climate change: the role of insurance). 2013.

[26] Stamovlasis D., Tsaparlis G. Applying catastrophe theory to an information-processing model of problem solving in science education. Science Education 2012:96(3):392-410. https://doi.org/10.1002/sce.21002 
[27] Wu Y. C., Chung S. L. Catastrophe risk management with counterparty risk using alternative instruments. Insurance: Mathematics and Economics 2010:47(2):234-245.

https://doi.org/10.1016/j.insmatheco.2010.04.002

[28] Gurenko E. N. Climate Change and Insurance: Disaster Risk Financing in Developing Countries. Climate Policy 2006:6:596-688.

[29] Grossi P., Kunreuther H., Windeler D. An Introduction to Catastrophe Models and Insurance. In: Grossi P., Kunreuther H. (eds) Catastrophe Modeling: A New Approach to Managing Risk. Catastrophe Modeling, vol. 25, 2005. Springer, Boston, MA. https://doi.org/10.1007/0-387-23129-3_2

[30] Surminski S., Bouwer L. M., Linnerooth-Bayer J. How insurance can support climate resilience. Nature Climate Change 2016:6(4):333-334. https://doi.org/10.1038/nclimate2979

[31] Le Quesne F, Tollmann J., Range M., Balogun K., Zissener M., Bohl D., Souvignet D., Schuster S., Zwick S., Phillip J., Wehnert B., Kreft S. The Role of Insurance in Integrated Disaster and Climate Risk Management: Evidence and Lessons Learned. GIZ Report no. 22, October 2017. Available: https://collections.unu.edu/eserv/UNU:6312/MCII_ACRI_1710020_Online-meta.pdf

[32] Subramanian A., Wang J. Reinsurance versus securitization of catastrophe risk. Insurance: Mathematics and Economics 2018:82:55-72. https://doi.org/10.1016/j.insmatheco.2018.06.006

[33] Montefiori M. Libertà di scelta e contratti prospettici: l'asimmetria informativa nel mercato delle cure sanitarie ospedaliere. (Freedom of choice and prospective contracts: the information asymmetry in the hospital healthcare market). Università di Genova, Dipartimento di Economia Pubblica, 2002. (In Italian).

[34] Avesani M. Le coperture assicurative nelle catastrofi naturali. (Insurance coverage in natural disasters). Universita di Pisa, 2014. (In Italian).

[35] Alpa G. Il diritto contrattuale comunitario. Un cantiere aperto. (Community contract law. An open construction site). Rivista giuridica sarda 2011:26(3):689-697. (In Italian).

[36] Charpentier A., Le Maux B. Natural catastrophe insurance: How should the government intervene? Journal of Public Economics 2014:115:1-17. https://doi.org/10.1016/j.jpubeco.2014.03.004

[37] Wrede P., Phily C., Wipf J. J., Tatin-Jaleran C., Garand D. Pricing for microinsurance: a technical guide. ILO's Impact Insurance Facility. 2016. [Online]. [Accessed 15.08.2020]. Available: http://www.impactinsurance.org/sites/default/files/MI\%20Pricing\%20Guide\%20FINAL.pdf

[38] Braun A. Pricing catastrophe swaps: A contingent claims approach. Insurance: Mathematics and Economics 2011:49(3):520-536. https://doi.org/10.1016/j.insmatheco.2011.08.003

[39] NAIAD 2020 Nature Insurance value: Assessment and Demonstration [Online]. [Accessed 22.10.2020]. Available: http://naiad2020.eu/

[40] Müller-Fürstenberger G. Schumacher I. Insurance and climate-driven extreme events. Journal of Economic Dynamics and Control 2015:54:59-73. https://doi.org/10.1016/j.jedc.2015.03.002

[41] Keskitalo, E. C. H., Vulturius G., Scholten P. Adaptation to climate change in the insurance sector: Examples from the UK, Germany and the Netherlands. Natural Hazards 2014:71(1):315-334. https://doi.org/10.1007/s11069-013-0912-7 